\title{
A View of the Future
}

The new seed-fertilizer technology or the Green Revolution got a firm hold in Indian agriculture by the middle sixties and thereafter spread rapidly, especially amongst wheat farmers. The shift in factor relationships that followed brought about a significant qualitative change in the input mix. A new phase in the development of Indian agriculture had begun. However, the high initial rate of growth in fertilizer inputs per hectare gave place to a slower one in the seventies, as the marginal product declined with an increase in the per hectare dose. Evidence of this can be clearly seen in Table 33 for nitrogenous fertilizers which dominate fertilizer consumption. In many of these years fertilizer consumption was determined by availability, because, at controlled prices, demand exceeded supply. This fact explains, to a large extent, the widely varying rates of growth in annual consumption. The trend in output during the decade was similar though more marked in the case of wheat than rice because the new technology for wheat was more sharply differentiated from the traditional one. During the later sixties as well as the seventies, the farmer concentrated mainly on those components in the new technology package which were immediately the most rewarding,viz., the new seed and nitrogenous fertilizers. Today we appear to be on the threshold of the next phase when the farmer will be forced to pay greater attention to the other, presently neglected, components.

With such structural changes interwoven in the input and output streams over a relatively short span of a decade and further changes in the offing, standard statistical procedures for making projections are likely to prove inept tools for visualising the future. To this is now added a one-move change in the price of fertilizers, whose magnitude takes it out of the proper range of these tools. We shall, therefore, attempt no quantitative projection of wheat and rice production, but will instead concentrate on anticipating how the farmers and the Government are likely to respond to the new fertilizer prices. It is easy to see that these responses will be strongly influenced by the imperative not only to feed a large and growing population but to feed it better.

To start with, let us reiterate the two salient features of the present situation which are revealed by our survey. First, the rise in fertilizer prices in June 1974 caused the farmers to reduce their fertilizer inputs, though the extent of the cut varied from crop to crop, region to region and even from farmer to farmer. While our survey was limited, other evidence is available (Appendix and 6 ) to show that, our findings reflect the general response of farmers throughout the country.

Secondly, though the inconstancy of weather complicated the impact of lower fertilizer inputs on production, the net return both for wheat and rice declined. Further, the net return for all crops grown by the farmer during the course of the full agricultural year also dropped and by a significant amount. The latter meant that the income of the farmer in 1974-75 fell below the 1973-74 level. This was true of all farms, irrespective of size and even of the farms in Muzaffarnagar. Here again there is evidence to corroborate our findings. [6] 
Table 33

Consumption and Price of Nitrogenous Fertilizers and Production of Wheat, Rice and Foodgrain in India $1964-65-1973-74$

\begin{tabular}{|c|c|c|c|c|c|c|c|}
\hline \multirow[b]{2}{*}{ Years } & \multirow{2}{*}{$\begin{array}{l}\text { Consumption } \\
\text { of nitro- } \\
\text { genous fer- } \\
\text { tilizers in } \\
\text { nutrients } \\
\text { (' } \infty \infty \\
\text { tonnes) }\end{array}$} & \multirow{2}{*}{$\begin{array}{l}\text { Percentage } \\
\text { increase } \\
\text { in the } \\
\text { consump- } \\
\text { tion of } \\
\text { nitrogen- } \\
\text { ous ferti- } \\
\text { lizers }\end{array}$} & \multicolumn{2}{|c|}{ Fertilizer prices } & \multicolumn{3}{|c|}{ Procuction (Million tonnes) } \\
\hline & & & $\begin{array}{l}\text { (Rs./ } \\
\text { tonne) }\end{array}$ & $\begin{array}{l}\text { sulphate } \\
\text { (Rs./ } \\
\text { tonne) }\end{array}$ & Wheat & Riœ & Foodgrains \\
\hline $\begin{array}{l}1964-65 \\
1965-66 \\
1966-67 \\
1967-68 \\
1968-69 \\
1969-70 \\
1970-71 \\
1971-72 \\
1972-73 \\
1973-74\end{array}$ & $\begin{array}{r}434.5 \\
547.4 \\
838.7 \\
779.5 \\
1,131.9 \\
1,360.3 \\
1,487.1 \\
1,755.4 \\
1,778.9 \\
1,835.0\end{array}$ & $\begin{array}{r}6.6 \\
26.0 \\
53.4 \\
-4.6 \\
41.6 \\
20.2 \\
9.3 \\
18.4 \\
1.0 \\
2.8\end{array}$ & $\begin{array}{r}633 \\
633 \\
680 \\
840 \\
860 \\
943 \\
923 \\
959 \\
1,050 \\
1,050\end{array}$ & $\begin{array}{l}445 \\
515 \\
515 \\
577 \\
577 \\
626 \\
626 \\
549 \\
600 \\
600\end{array}$ & $\begin{array}{l}12.29 \\
10.42 \\
11.53 \\
16.54 \\
18.65 \\
20.10 \\
23.83 \\
26.41 \\
24.92 \\
22.00\end{array}$ & $\begin{array}{l}39.03 \\
30.66 \\
30.44 \\
37.60 \\
39.76 \\
40.43 \\
42.23 \\
43.07 \\
38.63 \\
44.00\end{array}$ & $\begin{array}{r}89.90 \\
72.03 \\
75.05 \\
95.05 \\
94.01 \\
99.50 \\
108.42 \\
105.17 \\
95.20 \\
104.00\end{array}$ \\
\hline
\end{tabular}

Table 34

Consumption and Price of Phosphatic Fertilizers in India 1964-65 to 1973-74

\begin{tabular}{lcll}
\hline & $\begin{array}{l}\text { Consumption of } \\
\text { Phosphatic } \\
\text { fertilizers in } \\
\text { nutrients } \\
\text { ('ooo tonnes) }\end{array}$ & $\begin{array}{l}\text { Percentage } \\
\text { change in } \\
\text { the consump- } \\
\text { tion of phos- } \\
\text { phatic } \\
\text { fertilizers }\end{array}$ & $\begin{array}{l}\text { Fertilizer prices } \\
\text { Super-phosphate } \\
\text { Rupee/Tonne }\end{array}$ \\
\hline $1964-65$ & $147.7^{\star}$ & 26.6 & - \\
$1965-66$ & $132.2^{\star}$ & -10.5 & 249 \\
$1966-67$ & $248.6^{\star}$ & 88.0 & 312 \\
$1967-68$ & 236.5 & -4.9 & 312 \\
$1968-69$ & 389.2 & 64.6 & 282 \\
$1969-70$ & 419.8 & 7.9 & 319 \\
$1970-71$ & 462.0 & 10.1 & 392 \\
$1971-72$ & 564.0 & 22.1 & 353 \\
$1972-73$ & 587.4 & 4.1 & 385 \\
$1973-74$ & 649.9 & 10.6 & \\
\hline
\end{tabular}

^From 1964-65 to 1966-67, distribution figures were treated as consumption. 
Since the vagaries of weather and the attending uncertainties are likely to be with us, the only way to visualise the future is with references to 'normal' or average weather conditions. This is what the farmer does when he makes his decision on what inputs, and how much, he is going to use, and also the Government, when it decides on a policy or a programme to influence the production of foodgrains. The year 1974-75 was an average year in the sense that, while the weather conditions were below 'normal' for the summer crops, they were better than 'normal' for the winter crops. The production of foodgrains in that year according to recent official estimates was 104 million tonnes and compared unfavourably with $108 \mathrm{million}$ tonnes in 1970-71 and 105 million tonnes in 1971-72. A lower output, associated with a cut in fertilizer inputs, in a year which must be treated as equivalent to an average year represents a situation which would be worthy of concern to the Government as much as to the farmer who suffered a decline in his income. Both would thus try not only to restore the previous levels of fertilizer inputs but to resume, at least, the interrupted upward trend.

To retrieve loss in income the major avenue open to the farmer is to take another look at the new technology to find means to reduce production costs and especially to increase the efficiency of fertilizer use. Fortunately the farmer will find many and varied means available to him.of course we have already discovered an important one in our survey. Under the pressure of high fertilizer prices large farmers in Karnal reduced their input of $\mathrm{N}$ for paddy cultivation, which was already at the recommended level, and increased their input of $P O$ which was far below the recommended level. The substitution of $P$ for $N$ meant additional cost, compared to what the cost might have been had the farmer simply reduced the input of $N$. But the improvement in the fertilizer mix produced a marginal increase in the yield rate in a year of unfavourable weather when all other farmers suffered a decline. As a result, these farmers came out much better financially than others.

Indian farmers have been described as "nitrogen-crazy" and indeed for most of them fertilizer means nitrogen, probably because it produces immediately descernible results which they can readily appreciate. This attitude appears to be typical of the first phase in the adoption of the new technology. Like the large farmers in Karnal there is evidence to show that many others are finding it profitable to move similarly into the next phase. $\overline{7 /}$ It is legitimate to expect that the increase in fertilizer prices will speed up the process of raising the efficiency level of fertilizer use. The farmer will now be very anxious to acquire more of the existing knowledge on soil nutrients and their use.

It is also likely that the farmer will not confine his search for cost economies only to redressing the $N$, P ratio or even the $\mathrm{N}, \mathrm{P}$ and $\mathrm{K}$ ratio. There are several other ways of achieving greater economy in fertilizer use. Important among these are briefly:

(i) the integration of organic manures with chemical fertilizers, and application of combinations taking account not of a single crop, but of the whole cropping system. It is well known that nutrients applied to one crop leave a residue available to the next crop which is often not taken advantage of. When properly formulated combinations of fertilizers are used for a cropping system, these residues would be picked up and would raise the utilisation ratio of fertilizer inputs. 
(ii) it is common practice to give a large base application of fertilizers with heavy irrigation, whereas 'split' applications with light irrigation are much more efficient.

(iii) the recovery of applied fertilizer nitrogen by crops is generally low and especially in kharif (including paddy) crops, where it can be less than half. This amounts to a considerable loss which can be saved, at least to a large extent, by the simultaneous application of certain chemicals and also certain non-edible oilcakes which are much cheaper.

(iv) it is also known that closer spacing of plants, than is the normal practice, raises the yield rate with the same application of fertilizer.

(v) Early sowing achieves the same results.

(vi) micro-nutrients are still not used and would, if used along with fertilizers, raise the yield rate.

(vii) several varieties of new seeds have now been developed, of which one tends to give better results than others in similar agro-climatic conditions of a region. The adoption of this "dominant" seed would lead to an almost no-cost improvement for the farmer.

It is not necessary here to delve further into other areas of cost-reducing improvements in farming, but one might mention two, which are particularly important. It might have been noticed that our sample of farmers paid scant attention to plant protection, and though farmers in India may now be more vigilant in general than before, it is true that modern methods of plant protection are still not widely used. The other area of perhaps even greater significance, where progress is still meagre, is water management.

Clearly, all of these avenues of improvements cannot be adopted immediately, but the climate has been created in which the incentive for the farmer to do so has undergone a radical change. In the first instance, the incentive would be for the farmer to acquire new knowledge and the associated new techniques. There are implications here for the extension service and for a more vigorous use of mass media. To the extent that farmers' complacence inhibited the speedier adoption of information or know-how in the past, has been replaced by a sharpened awareness as recipients now could ensure gains even with the existing system. But this would also be the right time for innovations in the techniques of mass communication.*

The input of new knowledge usually implies additional risk for the farmer, which is further enhanced if additional cost is involved in complementary inputs. This acts as a deterrent to the adoption of innovations. The perception of risk depends not only on the additional outlay involved, but also on the base level of input use and the base level of household income.

In India majority of farms are either not irrigated or not well served with irrigation facilities and hence, either do not use fertilizers at all or use smaller doses than the farms in Karnal or Muzaffarnagar, both of which are relatively advanced districts. Since fertilizers, as much as any other input, are subject to diminishing returns, there is much to be gained in terms of output by transferring the

*India has just recently started a satellite TV programme specifically oriented to farmers. 
the marginal inputs of fertilizers from those farms which use high doses to those that still use relatively small doses or none. There is a prestigious body of opinion in the country 4,6 that would favour such a transfer. However, it should be recognised that control on irrigation is a facility which considerably improves the efficiency of fertilizer application and, therefore, its lack is an impediment. To the extent there is no agronomic bottleneck, the return on marginal cost of fertilizer inputs would be higher in farms using a low rather than a high dose. For the low-dose farms additional fertilizer application even at the present prices may be profitable. A good number of these farms are likely to be small with low incomes and hence, though innovative behaviour in their case may entail less risk, their perception of it, dominated by their low resource base, may magnify it.

There is another kind of small farm which applies a relatively high dose of nitrogen and secures higher per hectare yields than large farms. We seen such farms in our sample and several empirical studies have shown that this is indeed a common phenomenon. Varying explanations for it have been offered, but the one that appears to fit the case we have examined may well have a wider application. It is more meticulous care and greater attention to detail (through closer personal involvement and supervision) that small farmers give and the large farmers cannot, which explain their higher yields. However, despite this, the small farmer may not secure a better net return as he is likely to sell his output soon after the harvest when the prices are low, while the large farmer can hold stocks to secure a higher price later in the year. The small farmer, therefore, rarely gets the full benefit of his greater efficiency. This fact is an indication and proof of his vulnerability, and the more vulnerable he is, the greater the risk he takes for any additional rupee worth of input he uses. The other, and not unrelated, reason for his vulnerability is that credit on reasonable terms is not easily available to him. Indeed, if such credit were to become available to him to the extent of his needs, his ability to bear the risk of crop damage or failure due to adverse weather conditions, and his capacity to hold stocks would considerably improve.

In the past the small farmer has also found himself at a disadvantage in the market for fertilizers which has generally suffered from excess demand. His ability to secure supplies in such a situation has not been the same as that of the larger farmer who has more influence and better financial resources. Fortunately, the availability of fertilizers, of late, has considerably improved and this will be in his favour.

As a part of Government's 20 Point Programme, announced in June, 1975, it was proposed to set up a number of Regional Rural Banks. The first set of these banks have already been set up. It is the object of these banks to specifically meet he credit needs of the farmers and particularly of the small farmers. To make their operation more efficient they are to have a new type of management with personnel trained in agriculture and geared to understanding the problems of the farmers. Security-oriented policy for advances is to be replaced by a greater leeway for the manager to rely on his judgement of the borrower's potential to re-pay. Currently 50 such banks are planned and are expected along with cooperative societies and new branches of commercial banks to provide full coverage of institutional facilities for rural credit requirements of the entire country. 
Product prices and controls
If the existing plan for establishing Regional Rural Banks, or any modification with the same objectives, is carried through, it would considerably improve the ability of the smaller farmer to use more fertilizers. The economics of fertilizer use in these farms is manifestly superior and they, more than the farmers who already use high doses of fertilizers, are in a position to gain from increased use.

The return of our sample farmers need not have fallen had there been a compensatory rise in output prices. In the case of rice, because of lower output due to unfavourable weather and lower fertilizer application, the price rise was not enough to offset the increase in cost. The weather conditions for wheat were so favourable that the decline in output that would have occurred with lower fertilizer inputs was more than offset, and the consequent rise in output prevented a rise in price. This outcome was helped by the curbs on speculation successfully applied after the Emergency of June 1975. The rise in the cost of production (15.3 per cent for wheat and 39.6 and 26.9 per cent for IR-8 and Bansmati rice) was clearly of a magnitude that could not have been compensated for by a rise in the product price in a single year. But it is evident that one way by which the fall in the farmer's income will be restored is an increase in the product price that exceeds the increase in the cost of production, after allowing for such economies in cost as the farmer is able to make by his own efforts.

In India, the Government regulates the price of fertilizers as well as those of wheat and rice. While its direct control of the prices of wheat and rice is limited to the part that goes through the public distribution system, it also influences the open market price through imports, bufferstock releases/withdrawals and zonal restrictions on the movement of these foodgrains. In the wake of high inflation during 1972-74, the main thrust of policy has legitimately been to keep prices from rising. This has now been successfully achieved. The problem of adjusting output to input prices is in the process of being resolved.

Since the increase in fertilizer prices in June 1974, the Government has revised them downwards more than once, thanks mainly to the fall in import prices and a reduction in the proportion of imports in the total supply. With respect to wheat and rice prices too the Government has intervened,but to prevent them from falling below procurement prices. This effort continued through the 1975 kharif and the 1976 rabi seasons which produced record crops, thanks mainly to the extraordinarily good monsoon that year, but the prices nevertheless fell. Such weather - induced good harvests as we have had in 1975-76 can conceal the danger of a steep fall in output even with average weather conditions. It is necessary, therefore, to create the conditions, as soon as possible, to restore fertilizer consumption not only to the 1973-74 levels but also to the previous rising trend.

Everyone is familiar with the inherent conflict in simultaneously satisfying both the farmer and the consumer. What is a good price for the former is bad for the latter. The Government tries to resolve this conflict by taking upon itself the burden of a subsidy for the consumer's benefit. The principal difficulty in raising the price for the producer is that it directly commits the Government to a higher burden of subsidy because the resistance to a rise in the consumer's price is strong. One answer to this problem seems to lie in taxing agricultural income, which is currently not taxed, to pay for the additional subsidy*.

*This argument is developed further in $/ 8 /$.

page 66 
A higher procurement price would particularly help the farmers who tend to sell their surplus soon after the harvest when the gap between the procurement price and the market price is the narrowest. It would also help in procuring more foodgrains and thereby in extending the public distribution system with gains to the low income consumer. Meanwhile the additional benefit derived by the larger farmer if syphoned off through tax would restore the desired balance.

Whether the Government follows this line of approach or another, its regulatory powers are availble and could be used to bring about such price adjustments as to make it possible for the farmers to use more fertilizers. A skilful use of these powers would indeed be necessary as the crude oil prices are not expected to decline and may be raised periodically. Fine adjustments would need to be made in the discriminatory pricing policy of oil products already in operation to minimise the burden of price increases for crude oil on fertilizers. Simultaneously, a flexible foodgrain pricing policy would be required to reflect the changes in fertilizer prices.

Besides its control on prices there are certain other controls that the Government exercises. Many of these relate to the distribution of fertilizers. Although none of the farmers in our sample said that any of the controls inhibited them from using the amount of fertilizers they desired, it is a fact that, in many regions such controls proved a positive bottleneck to fertilizer consumption. Requirement of a permit to buy fertilizers, restriction on the amount that could be bought and the dealer from whom it could be bought, delays in issuing the permit, restriction on the movement of fertilizers between zones, states and even districts, etc., were the kind of controls that were in use in 1974-75. Some of them, for instance, the permit system, were scrapped even before the year was out.

The important point, however, is that the need to exercise direct physical control over distribution arises from a situation where demand exceeds supply at the controlled price. Inadequate domestic production and foreign exchange constraints on imports have been the basic reasons for supply shortfalls. Sometimes the methods chosen for control of distribution may not be the best, and always inefficiencies tend to creep in. These can cause unsatisfied demand to co-exist with surplus stocks in warehouses and imbalances to arise between regions, some regions experiencing shortages while others having surpluses; the latter even when the aggregate supply is adequate. To this, deficiencies in the distribution network and lack of institutional credit facilities also contribute in no small measure.

Since 1974-75 the domestic supply position has radically changed. The domestic output of nitrogenous fertilizers (N) in 1973-74 was 1.05 million tonnes and in 1974-75, 1.19 million tonnes or 13.3 per cent higher. In 1975-76, as new capacities came on stream, a much more substantial increase is expected. The increase in domestic production of phosphatic fertilizers in the same period was negligible - from 0.324 milition tonnes of $\mathrm{P} O$ to 0.327 million tonnes - and it is likely to fall in 1975-76 mainly due to the slack in demand. The fertilizer industry has a priority in Indian planning and the Fifth Plan production target for 1978-79 is set at $4.0 \mathrm{million}$ tonnes of $\mathrm{N}$ and $1.25 \mathrm{million}$ tonnes of $\mathrm{P} O$. An improvement in domestic production is, however, not enough by itself. It needs to be backed by a strengthening of the distribution network and an extension of institutional credit facilities. 
The second year after the increase in fertilizer prices
Even before the June 1974 rise in fertilizer prices the rate of increase in fertilizer demand had begun to slow down. This was not an altogether unexpected phenomenon. It was natural that while the new technology was spreading rapidly, the demand for fertilizers should also increase rapidly. But as the increase in acreage adopting the new technology became progressively smaller the rate of increase in the demand for fertilizers slowed down. Had the fertilizer price rise not taken place, one would have expected that over the next decade, (i) the rate of increase in fertilizer consumption would be lower than in the past decade though each year more fertilizers would be consumed, (ii) there would be a better spread in the use of fertilizers between farms of different sizes and between different regions, and ( $\mathrm{i} i \mathrm{i}$ ) the $\mathrm{N}: \mathrm{P}: \mathrm{K}$ ratio of fertilizer inputs per unit of land, which currently deviates widely from what is recommended, would improve, raising the efficiency of fertilizer use. We have argued earlier that the rise in the price of fertilizers would accelerate the realisation of the last expectation. There are also good reasons to believe that a spread of fertilizer use may not be inkibited by the rise in fertilizer prices and may even be helped by it.

The agricultural year 1975-76 started with the cheerful news that the monsoon had broken in good bountiful showers all over the country. The course of the monsoon later fulfilled the early promise and the season ended with one of the best rains India has had for years. Estimates of both kharif and rabi harvests rate the output to be the highest ever. There is wide agreement that, foodgrain production in 1975-76 would reach a level of 115 million tonnes (rice 50 million tonnes and wheat 28 million tonnes) against the earlier peak of 108 million tonnes (rice 43 million tonnes and wheat 26 million tonnes) in 1971-72 and last year's production of a little over 101 million tonnes.

Two obvious questions arise. Was this increase in production due entirely to the excellent monsoon or, should one assume that the shock of the high fertilizer prices has already been absorbed by the farmer and, having adjusted himself to the new circumstances, he is back on the earlier use trend. That the weather has contributed a good part of the output increase is abundantly clear. But the extent to which the farmer has restored the previous year's cuts in fertilizer consumption can only be judged in the light of such information as is available.

One incontrovertible fact is that the dealers' offtake during the kharif season increased and this is being taken as an index of the revival in fertilizer demand*. This may, however, not be a true index for two reasons: (i) fertilizer consumption by farmers is always lower than the dealers' offtake and the gap can vary widely from time to time! (ii) dealers had been expecting a reduction in fertilizer prices and were hopeful that their demand for a better commission wald be met and on both counts were being deliberately slow in lifting stocks. Eventually both of their expectations were realised and it was only after this that their offtake of fertilizers picked up significantly. One does not, of course, know to what extent this increase is meant to replenish the dealers' run-down stocks, or wheather it amounts to no more than a refurbishment of the normal inventory. Another and, perhaps, a more serious

*Data furnished at Zonal Conferences of the Minj.stry of Agriculture, Government of India, shows a substantial increase in the consumption of $\mathrm{N}$, but doubts are expressed whether this represents true consumption. 
reason for doubt arises from the fact that between last year and now, while fertilizer prices, even after some reduction, are still very much higher than the pre-June 1974 prices, the price of foodgrains have either not risen at all or have declined. Expectations also are clearly not for a rise. In these circumstances the reasons why farmers' behaviour with respect to the use of fertilizer inputs should be different this year from last year become complex.

The answer to this question can only be conjecture at this stage. Firstly, the Fertilizer Association of India investigating the fall in fertilizer demand last year concluded that, on the whole, the restrictive nature of controls on the distribution of fertilizers, prevalent in many States at the time, was the most important reason (see Appendix). It is quite obvious that when two factors were simultaneously inhibiting consumption, it would be highly arbitrary to attribute the fall to any one of them. Nevertheless, it is quite possible that the fall in the demand for fertilizers, or more precisely a fall in consumption in those states where restrictive controls were being employed, might not have been as great if there had not been controls. To that extent, one can expect the consumption of fertilizer to go up, since most of these controls have now been removed.

Secondly, the type of change in the NPK combination of fertilizer inputs in large rice farms found in the survey in Karnal might have occurred more widely this year, raising the demand for phosphatic fertilizers, and perhaps of nitrogenous fertilizers, too, at a new NP combination. However, indications, such as there are, tend to show that, on the whole, the demand for phosphatic fertilizers fell. This, to the extent the farmer regards $\mathrm{N}$ and $\mathrm{P} O \mathrm{O}$ as substitutable, would increase the demand for $\mathrm{N}$.

Thirdly, the good start of the monsoon rains this year might have been read by famers - and as it turned out rightly - as a fair indication of a good season; hence they might have perceived the risk involved in using a larger input of fertilizers, particularly $\mathrm{N}$, much less than last year. This would, of course, induce them to raise their input of $\mathrm{N}$.

Finally, the farmer might have accepted the change in fertilizer costs, after the revisions, as irreversible and based on last year's experience decided to put in more fertilizer at the slightly lower prices in a bid to raise his income even at a higher risk.

Which of these reasons has played the more important role if, in fact, there has been a significant increase in fertilizer consumption, will only be revealed when the facts come to be known more fully. Meanwhile, one is confronted with a situation in which for three crop seasons in a row - rabi, kharif and rabi - a slack demand for fertilizers (a fall in the first) been accompanied by the best harvests ever.

Later when men look back on the events of these years they are likely to mutter a prayer of gratitude for the good monsoons which most benevolently intervened to convert a period fraught with potential crisis into a period of blessing. Even today one can perceive that a breathing space has been gained to face a challenge which the farmer and the Government must meet. On the food front India does not have too many options and the compulsions to produce more are strong. Indian yields of both wheat and rice are still low compared with many other countries. There is 
scope, therefore, for considerable increases for which technology as well as infrastructure are available. The high cost of fertilizers should spur the farmers on to innovative action, while Government policy should aim to ensure a suitable climate for it. With the right steps taken, there would be every reason to expect a rising trend in production in the future.

We have assumed all along that the radical revision in fertilizer prices has come to stay. The initial response in India to the steep rise in oil prices was to consider coal as an alternative raw material for manufacturing fertilizers. India's known reserves of coal are estimated at 80,000 million tonnes which can last, at the present rate of consumption, for more than 100 years. Mining costs are comparatively low and at the new oil prices a shift to coal-based technology for fertilizer production seemed to be clearly indicated. Without any loss of time the Government went ahead with plans to set up three coalbased plants and the first of these is now nearing completion.

Since this initial response several things have happened to add new dimensions to the problem. First of all, world prices of fertilizers, which had rocketed upwards, have stabilised at lower levels. It seems now that the shock of the rise in oil prices has been absorbed by the world fertilizer industry. Secondly, India's effort at exploring off-shore possibilities for oil have borne fruit beyond early expectations. Oil struck in the Bombay High field is very promising and it is expected that by 1976-77, 2 million tonnes of crude oil will be available and that this amount will rise to 10 million tonnes by 1980 . Meanwhile oil has also been struck at Bassein, close to Bombay, and this field also appears to be full of promise. These discoveries have led to optimism in respect of other existing and planned areas of exploration. An increase in the proportion of domestic crude in the total supply would reduce the annual import bill and possibly the domestic cost of oil. It would also increase the availability of lighter distillates since the lighter Bombay High crude would yield a higher proportion of the lighter fractions. Thirdly, Indian coal, now amongst the cheapest in the world, is due for some increase in price. Coal is a nationalised industry and its price is controlled. Cost of raising it has been rising and there is need for considerable investment for modernising the mining operations, for beneficiation to raise the quality of coal and for opening additional mines. Investment in all these is overdue and the industry is anxious to lose no more time. Those who followed the debate on the Fifth Plan target for coal, would recall that considerable doubt was expressed by those with knowledge of the industry about the possibility of reaching the target, mainly on account of inadequate investment in the industry in the past and the relatively long gestation period for making a new mine operative. The coal industry clearly requires to plough back funds for development. However, at the current coal prices this seems a difficult task. It is, therefore, quite on the cards that there may be a significant revision in the coal prices in India.

Fourthly, recently Indian exports have been growing at highly satisfactory rates and the balance of payments position has improved. As a result, the Indian rupee has gained strength. As the gap between the market value of the rupee and the official exchange rate narrows, economis cost of imported oil would tend to get closer to its financial cost. In estimating the cost of imported oil normally, certain premiums of foreign exchange have been allowed which may 
now be much lower than assumed earlier and may also fall further. This will have relevance to the relative cost of producing fertilizer from coal or oil.

It would seem, therefore, that the initial comparative advantage of coal would now seem to be less than previously estimated. However, the major question in producing fertilizer from coal in India is the technology based on noncoking and not coking coal. The plant which is nearing completion now is thus in the nature of an experiment to test the commercial viability of the currently known technology. At present, it should be kept in mind that, the capital cost for a coal-based plant is comparatively high and the gestation lag longer.

A new possibility of considerable significance has now emerged with the availability of gas from the Bombay High and Bassein structures as well as from other prospective fields. As the technology with gas as feedstock is well established, if adequate gas as now expected does become available, it would further widen the choice of $r a w$ materials for manufacturing fertilizers. Whether it is coal or gas, one can look forward to a mix of fertilizer feedstock which would be an improvement on the present reliance on naphtha.

The question of the future feedstock for fertilizer manufacture in India would, however, take some time to be resolved. Meanwhile the farmer has already shown the capacity to absorb higher fertilizer prices either by his willingness to take greater risks or his efforts to economise through improved cultural practices. The Government's drive to make institutional credit available more widely would reduce risk and an improvement in the farmer's cultural practices would raise productivity levels to offset the rise in cost. In any event, there is sufficient evidence to suggest that the increase in the price of crude oil will not act to the detriment of the growth of agriculture in India even if the base for fertilizers continues to be oil. 